International experience as a microfoundation of foreign subsidiary performance: $\mathrm{A}$ multilevel model

By: Marketa Rickley, I-Heng (Ray) Wu, and Eean Crawford

Rickley, Marketa, I-Heng Wu and Eean Crawford. 2021. International experience as a microfoundation of foreign subsidiary performance: A multilevel model. In S. Taneja (Ed.), Proceedings of the Eighty-first Annual Meeting of Academy of Management, 6 pages. https://doi.org/10.5465/ambpp.2021.28

***(C) 2021 Academy of Management. Reprinted with permission. No further reproduction is authorized without written permission from the Academy of Management. ***

\begin{abstract}
:
In multinational companies, international experience by managers is considered a source of competitive advantage. Yet we know little about whether the positive consequences of personal international experience persist when aggregated in top management teams (TMTs). Are certain experiential, relational, or structural TMT configurations more effective at converting personal knowledge from international experience into organizational performance? Drawing on knowledge integration and small groups research, we develop a multilevel model of compositional emergence to define how personal international experiences aggregate from the individual to the collective. We then explore how TMT differences in experiential, relational, and structural configurations of international experience affect performance. We test our predictions using a cross-national and multilevel dataset on foreign-owned banks. The data include detailed information on top managers' demographic, educational, and professional backgrounds ( $\mathrm{N}=270$ TMTs, nested within 60 foreign subsidiaries, and 28 multinational banks), ten years of financial performance data, and covariates from different levels (e.g., TMT, subsidiary, MNC, home country, host country). By theoretically and empirically linking individual differences in international experience to subsidiary performance through team-level knowledge integration mechanisms, we contribute to the search for microfoundations of competitive advantage using the knowledge- and resource-based views in an international context.
\end{abstract}

Keywords: top management teams (TMTs) | international experience

Article:

***Note: Full text of article below 


\title{
INTERNATIONAL EXPERIENCE AS A MICROFOUNDATION OF FOREIGN SUBSIDIARY PERFORMANCE: A MULTILEVEL MODEL
}

\author{
MARKETA RICKLEY \\ University of North Carolina at Greensboro \\ 516 Stirling Street, Greensboro, NC 27412 \\ I-HENG (RAY) WU \\ University of Iowa \\ EEAN CRAWFORD \\ University of Iowa
}

\section{INTRODUCTION}

In multinational companies (MNCs), international experience by top managers is considered a knowledge-based source of competitive advantage (Morris, Snell, \& Björkman, 2016; Tasheva \& Nielsen, 2020). Defined as exposure to or interactions with members or elements of a different culture (Maddux, Lu, Affinito, \& Galinsky, 2021), international experience by individuals is associated with positive personal and organizational outcomes. For individuals, international experience builds cross-cultural competencies (Caligiuri \& Bonache, 2016), information-processing capabilities (Greve, Nielsen, \& Ruigrok, 2009), strategic thinking (Dragoni et al., 2014), managerial cognition (Maitland \& Sammartino, 2015), and global dynamic managerial capabilities (Tasheva \& Nielsen, 2020). Firms led by internationally experienced CEOs outperform their rivals (Carpenter, Sanders, \& Gregersen, 2001; Daily, Certo, \& Dalton, 2000; Le \& Kroll, 2017), as do firms with greater proportions of internationally experienced members on the board (Volonté \& Gantenbein, 2016). In sum, previous research broadly indicates that international experience is desirable (Takeuchi \& Chen, 2013).

Despite these important insights, we know little about what happens when top managers' international experience portfolios combine (Maddux et al., 2021). Do the positive consequences of personal international experience persist when pooled in top management teams (TMTs)? This is a critical theoretical issue because international management is predominantly performed in teams (Zander et al., 2015). This leads to two interesting and unexplored research questions. How does aggregate TMT international experience, beyond that of the CEO, influence organizational performance? Are certain relational and structural TMT configurations more effective at converting members' personal international experience into performance?

To develop theory on how personal knowledge from international experience aggregates in a team setting to affect higher-level performance outcomes, we draw on resource-based (Barney, 1991) and knowledge-based (Grant, 1996) theories of the firm, literature on knowledge integration (Gardner, Gino, \& Staats, 2012; Zahra, Neubaum, \& Hayton, 2020), and small groups research. While strategy research posits that effective group-level knowledge integration depends on the team's experiential, relational, and structural resources (Gardner et al., 2012), research in organizational psychology emphasizes the process of emergence from individual experience to the collective (Kozlowski \& Klein, 2000a; Mathieu, Tannenbaum, Donsbach, \& Alliger, 2014). We integrate these insights to develop a multilevel model of knowledge integration from international experience in TMTs. Its purpose is to explain how TMT members' cumulative 
stocks of international experience and the team's relational and structural resources affect foreign subsidiary performance.

\section{THEORETICAL BACKGROUND AND HYPOTHESES}

MNC performance depends on organizational abilities to understand multiple, heterogeneous competitive environments and on how well the organization integrates the knowledge that has been created and transferred across national borders (Kogut \& Zander, 1993; Nonaka, 1990; Westney, 2001). The benefits of effective knowledge integration are arguably the greatest at the foreign subsidiary level, where MNCs' local, regional, and global interests converge - and where the promise of knowledge-based competitive advantage either materializes or breaks down. Members of foreign subsidiary TMTs are critical to this knowledge integration process. Subsidiary TMT members not only create an interface between the subsidiary, its host market environment, and the broader network of MNC business units, but they also exercise significant discretion and power over strategic decision making (Vora, Kostova, \& Roth, 2007). Subsidiary TMT members' tacit knowledge therefore influences subsidiary performance (Finkelstein, Hambrick, \& Cannella, 2009).

\section{International Experience as Tacit Knowledge}

Exposure or interaction with a foreign culture allows individuals to develop tacit knowledge that is valuable, rare, and difficult to imitate or substitute (Greve et al., 2009; Le \& Kroll, 2017). International experience builds context-specific know-how of particular countries that is valuable in international business (Carpenter et al., 2001; Daily et al., 2000). It also builds individuals' context-general skills and competencies (Le \& Kroll, 2017) that are essential at higher management levels (Mendenhall, 2001) but are difficult to acquire through other means (Sambharya, 1996). Because individuals develop international experience from personal interactions in a particular place at a particular time, the earned knowledge is rare and inimitable. Bundling individuals' tacit knowledge from international experience in a TMT creates a socially complex, causally ambiguous, and path dependent resource that is difficult for competitors to imitate or substitute (Teece, Pisano, \& Shuen, 1997) and that contributes to competitive advantage (Carpenter et al., 2001; Daily et al., 2000). We use these insights as our theoretical foundation for connecting tacit knowledge from international experience to performance.

\section{Team-Level Knowledge Integration}

One of the key insights of the resource-based and knowledge-based views is that firm performance is shaped not only by resource stocks but also the way in which resources are coordinated, combined, and deployed (Teece et al., 1997). Creating and capturing value from knowledge-based resources thus depends not only on accumulating knowledge but on integrating it productively (Kogut \& Zander, 1992). Knowledge integration is defined as "an organizational capability for creating novel combinations of different strands of knowledge, which have utility for solving organizational problems, ... and which derive from individual and group contributions, facilitated by both formal and social processes" (Zahra et al., 2020: 163). The definition highlights that although knowledge resides in individuals (Grant, 1996), firms' 
abilities to derive value from it rely on cross-level mechanisms that aggregate individually-held knowledge and transform personal to group knowledge (Kozlowski \& Klein, 2000b).

Available research points to three types of resources that underlie teams' knowledge integration capabilities: experiential, relational, and structural resources (Gardner et al., 2012). The logic behind this conceptualization is that team-level knowledge integration depends not only on whether team members possess sufficient relevant expertise, but whether the relationships between team members and the structural configuration of the team are conducive to knowledge exchange and recombination. Following Gardner et al. (2012), a team's experiential resources refer to the total amount of relevant know-how earned through members' personal experiences. Relational resources represent the extent of shared or overlapping experiences among members. Structural resources refer to the distribution of experiential resources in the team.

\section{Experiential resources}

A team's ability to derive value from knowledge is greater when its members can access more accumulated knowledge (Gardner et al., 2012). Foreign subsidiaries led by TMTs with greater breadth of international experience have several advantages. With a broader range of countries of experience, the team can access a more extensive knowledge base. Greater breadth allows for comparison, validation, and integration of knowledge across multiple distinct experiences. Indeed, breadth of information, expertise, and perspectives from international experience have been shown to promote team performance (Stewart, 2006) through enhanced creativity (Jang, 2017), innovativeness (Bantel \& Jackson, 1989), and decision quality (Gruenfeld, Mannix, Williams, \& Neale, 1996). The quality of the TMT's strategy formulation and decision making also likely increases with its depth of international experience. Deep experiences stimulate knowledge elaboration and integration processes among team members (Van Knippenberg, De Dreu, \& Homan, 2004). They spur information exchange, inspiring individual-level processing and more careful validation of one's own and others' contributions, leading to more profound group discussions and formulation of comprehensive solutions (Bunderson \& Sutcliffe, 2002; Van Knippenberg et al., 2004).

Hypothesis 1a: Cumulative breadth of international experience in the TMT is positively associated with subsidiary performance.

Hypothesis 1b: Cumulative depth of international experience in the TMT is positively associated with subsidiary performance.

\section{Relational Resources}

In order to realize organizational benefits of knowledge exchange, idea recombination, and enhanced team cognition, TMT members must not only possess experiential resources, but the team must also have relational resources to ease the knowledge integration process (Gardner et al., 2012). Because international experience is tacit knowledge that is transferred from person to person, relational resources are needed to transform personal knowledge into performanceenhancing capabilities and sources of competitive advantage. 
Subsidiary performance can improve when more TMT members have more countries of international experience in common. With stronger and more abundant relational ties based on overlapping domains of international experience, the country-specific knowledge earned during individuals' experience abroad is more likely to be voiced, discussed, and considered by the group. In contrast, without overlapping knowledge domains, it is difficult for team members to integrate multiple sets of information and arrive at a common understanding (Dougherty, 1992; Okhuysen \& Bechky, 2009). Without overlap, the informational differences associated with breadth of international experience are less likely to be productive. Similarly, overlap in depth of international experience can signify that two individuals have developed similar kinds of tacit knowledge. These commonalities all help ease the burden of communication and promote collaborative dynamics within a team.

Hypothesis 2a: Cumulative shared breadth of international experience in the TMT is positively associated with subsidiary performance.

Hypothesis 2b: Cumulative shared depth of international experience in the TMT is positively associated with subsidiary performance.

\section{Structural Resources}

Team effectiveness also depends on the distribution of resources among team members (Crawford \& Lepine, 2013; Katz \& Kahn, 1978). Distribution patterns have implications for who interacts with whom and the quality of their interactions. This, in turn, influences overall TMT functioning and hence TMTs' abilities to shape organizational outcomes (Mathieu et al., 2014).

To model the distribution of TMT members' international experience portfolios and explore relationships between structural resources and subsidiary performance, we use the three types of diversity described by Harrison and Klein (2007): disparity, separation, and variety.

TMTs characterized by low disparity in international experience will benefit from comparable levels of context-general competencies held by individual team members, including enhanced information processing (Greve et al., 2009), capacities for problem solving (Maddux \& Galinsky, 2009), strategic thinking (Dragoni et al., 2014), communication (Backmann, Kanitz, Tian, Hoffmann, \& Hoegl, 2020), and trust (Chua, Morris, \& Mor, 2012). In contrast, high disparity in international experience among TMT members creates difficulties for integrating the available knowledge. TMTs characterized by high disparity in international experience will struggle to convert it into subsidiary performance.

Hypothesis 3a: Greater disparity in TMT members' breadths of international experience is negatively associated with subsidiary performance.

Hypothesis 3b: Greater disparity in TMT members' depths of international experience is negatively associated with subsidiary performance.

TMTs characterized by low separation (such as when members all have high or low levels of international experience) will benefit from the psychological comfort of team homogeneity. Interacting with similar others begets greater cooperation and interpersonal trust (Locke \& Horowitz, 1990), allowing for voicing and elaboration of knowledge. While similar 
members may enjoy greater cohesion within their subgroup, greater separation between subgroups is associated with reduced productive communication (Van Knippenberg et al., 2004), increased interpersonal conflict (Li \& Hambrick, 2005), and poor organizational performance (Cooper, Patel, \& Thatcher, 2014; Van Knippenberg, Dawson, West, \& Homan, 2011).

\section{Hypothesis 4a: Greater separation in TMT members' breadths of international} experience is negatively associated with subsidiary performance.

\section{Hypothesis 4b: Greater separation in TMT members' depths of international experience is negatively associated with subsidiary performance.}

Higher levels of international experience variety can improve performance because additional, nonredundant country-specific experiences add new information to a team's knowledge base. Information diversity promotes information processing, creativity, and problem solving in teams (Bell, Villado, Lukasik, Belau, \& Briggs, 2011), giving TMTs greater awareness of foreign contexts and allowing them to make more informed choices, leading to higher subsidiary performance.

\section{Hypothesis 5: Greater variety in TMT members' composite international experience is positively associated with subsidiary performance.}

\section{METHODS}

We test our hypotheses in the banking industry in Central and Eastern Europe, where we take advantage of disclosure practices that make subsidiary-level data public. Foreign-owned banks (i.e., the national-level subsidiaries of multinational banks) in this region publish annual reports where they voluntarily present not only their financial results, but also the composition of their TMTs, including members' names, functional roles, and experiential backgrounds. To create a multilevel dataset spanning individual, TMT, subsidiary, MNC- home and host country level variables, we supplemented the subsidiary-level annual report data with information from additional sources (e.g., LinkedIn, MNC annual reports, industry reports, etc.).

The unit of analysis is the TMT-subsidiary-year. We began with 70 subsidiaries in our initial sample and gathered a six-year panel of TMT composition (2005-2010) and a ten-year panel of subsidiary profitability (2003-2012). After excluding observations with missing information and TMTs with three or fewer members, we retained 60 subsidiaries across 12 host countries, belonging to $28 \mathrm{MNCs}$ domiciled in 12 home countries. Our final sample is an unbalanced panel of 270 TMT-subsidiary-year observations.

\section{RESULTS}

Hypothesis $1 \mathrm{a}$ is unsupported $(\beta=0.03, p$ value $=0.31)$. Hypothesis $1 \mathrm{~b}$ is unsupported $(\beta$ $=-0.01, p$ value $=0.39)$. Hypothesis $2 \mathrm{a}$ is unsupported $(\beta=0.03, p$ value $=0.27)$. Hypothesis $2 \mathrm{~b}$ is unsupported $(\beta=0.01, p$ value $=0.06)$. Hypothesis $3 \mathrm{a}$ is unsupported $(\beta=-0.25, p$ value $=$ $0.14)$. Hypothesis $3 b$ is supported $(\beta=-0.42, p$ value $=0.00)$, indicating that a one-year increase in the coefficient of variation between TMT members' personal years of international experience is associated with a 0.42 percentage point decrease in subsidiary ROA. Hypothesis $4 \mathrm{a}$ is 
supported $(\beta=-0.55, p$ value $=0.02)$, indicating that a one-country increase in the standard deviation of TMT members' personal country counts is associated with 0.55 percentage point decrease in subsidiary ROA. Hypothesis $4 \mathrm{~b}$ is likewise supported $(\beta=-0.16, p$ value $=0.00)$, indicating that a one-year increase in the standard deviation of TMT members' personal years of international experience is associated with a 0.16 percentage point decrease in subsidiary ROA. Hypothesis 5 is supported $(\beta=0.29, p$ value $=0.04)$, indicating that a more even distribution of years of international experience across country categories by TMT members is beneficial to subsidiary performance. Specifically, a one-unit increase in entropy is associated with a 0.29 percentage point increase in subsidiary ROA.

\section{DISCUSSION}

Our results demonstrate that the structural distribution of international experience among TMT members is critical for converting individual international experience into financial performance. Specifically, financial performance improves with more equal distributions of international experience across TMT members and across country categories. We also find evidence of performance benefits from members having shared experience abroad, which corresponds with recent research highlighting the importance of overlap among team members' personal ranges of experience (Honoré, 2021; Tasheva \& Hillman, 2020).

Our findings reaffirm the importance of international experience for financial performance in international contexts but offer several contributions and clarifications. First, in response to calls to develop more multilevel theory that explains individual and group influences within teams (Meyer, Li, \& Schotter, 2020), we craft and empirically test a multilevel model linking individual knowledge from international experience to financial performance. We thereby advance the literature on international experience, which focuses extensively on international experience at the individual and firm level but seldom at the team level (Maddux et al., 2021).

Second, our multilevel exploration contributes to the search for microfoundations of performance in international contexts, which have thus far remained understudied (Foss \& Pedersen, 2019; Meyer et al., 2020). In line with the resource-based view and dynamic capabilities research (e.g., Teece et al. (1997)), our results demonstrate that organizational performance is determined not simply by accumulated experiential resources but by the way in which these resources are configured and combined. Given that "it is largely individuals that are carriers of the tension between home and abroad that is central to so much IM research" (Meyer et al., 2020: 1617), our focus on subsidiary TMT members provides a framework for thinking about how international experiential backgrounds can foster action and interaction among individuals facing dual pressures of institutional and organizational environments.

Third, in answering the call to identify situations where international experience by individuals may be helpful or harmful to organizational outcomes (Takeuchi \& Chen, 2013), we find that TMTs with more cumulative international experience can underperform less experientially endowed TMTs, if (i) the more endowed TMTs are characterized by greater separation between the experienced and inexperienced team members in terms of country counts or years spent abroad, or if (ii) a disproportionate amount of years of experience is held by one or a few members. Put simply, a downside of accumulated international experience can emerge from its suboptimal configuration in a team.

\section{REFERENCES AVAILABLE FROM THE AUTHORS}

